\title{
Porosity Distribution and Differentiation Of Different Types Of Fluids In Reservoir Of Sawan Gas Field, Lower Indus Basin, Pakistan
}

\author{
M. Asada, H.U. Rahimb* \\ a Department of Earth Sciences, Quaid-i-Azam University, 45320, Islamabad, Pakistan. \\ b Pakistan Museum of Natural History, Garden Avenue, Skakarparian, 44000, Islamabad, Pakistan. \\ *Corresponding Author Email: hamadrahim@gmail.com
}

\section{DOI: $10.2478 / p j g-2019-0004$}

\begin{abstract}
:
The lower Indus basin is one of the prolific basins in Pakistan in which the C-interval of lower Goru formation act as a reservoir. With the help of petrophysical interpretation production zone is recognized and also porosity is calculated at the reservoir level. Through porosity we are able to calculate Ksat .A model based inversion of 2D seismic inversion was performed to ascertain three dimensional dispersion of acoustic impedance in the investigation zone and we have recognized new areas where porosity distribution is maximum and site which is suitable for new well. Porosity and Acoustic impedance are typically contrarily relative to each other. Presently porosity can be anticipated in seismic reservoir characterization by utilizing acoustic impedance from seismic inversion far from well position.
\end{abstract}

Keywords: Goru Formation, Acoustic Impedance, Porosity, Model Base Inversion

\subsection{Introduction:}

Sawan is the study area located in Khairpur District of Sindh province, Pakistan (Figure 1). This area lies near the edge of Lower Indus Basin. Sawan area is well-known for its gas production, so it is often called as Sawan gas field which is located in the Thar Desert, approximately 300 kilometers north-east of Karachi, was discovered in 1998 [1-3]. The whole data use is based on the distinction of main reservoir such as C-interval of Lower Goru Formation of Sawan area. The study of chemical and physical properties is done with the help of petrophysical analysis. Broadly speaking, usefulness of petrophysical investigation is to change over the raw log information into estimated amounts of oil, gas and water in a development [4-7]. The petrophysical log understanding is important tool feasible for both geologist and a geophysicist. Utilizing seismic information as a hydrocarbon marker lies in the effective extraction of helpful petrophysical parameters [8]. A critical task for petrophysical examination is to acquire proper physical parameters for indicating fluids and lithology from log information [9]. Gassman fluid substitution equation is applied to find out the impact of fluid substitution on seismic velocity and density.

\subsection{Regional Geology}

The Sawan gas field lies in the middle Indus basin, in the eastern border of Pakistan. The study area is bounded by the Sargodha High to the north and by the Jacobabad and Mari-Kandkot Highs to the south (Figure 1) [10]. The Indian Shield bounds the eastern side of the study area, whereas the Kirthar and Suleiman foldand- thrust belts mark its western boundary (Figure 1) [3,11]. Regional geological data indicate that the structural evolution of the Sawan gas field was closely controlled by three post-rift tectonic events: (a) Late Cretaceous uplift and erosion, (b) NW-trending thick skinned wrench faulting, and (c) Late Tertiary to present-day tectonic uplift of the Jacobabad and Khairpur Highs [12]. These latter structural highs played an important role in the formation of structural and stratigraphic traps, not only in the Sawan area, but also in multiple oil and gas fields in the middle Indus basin.
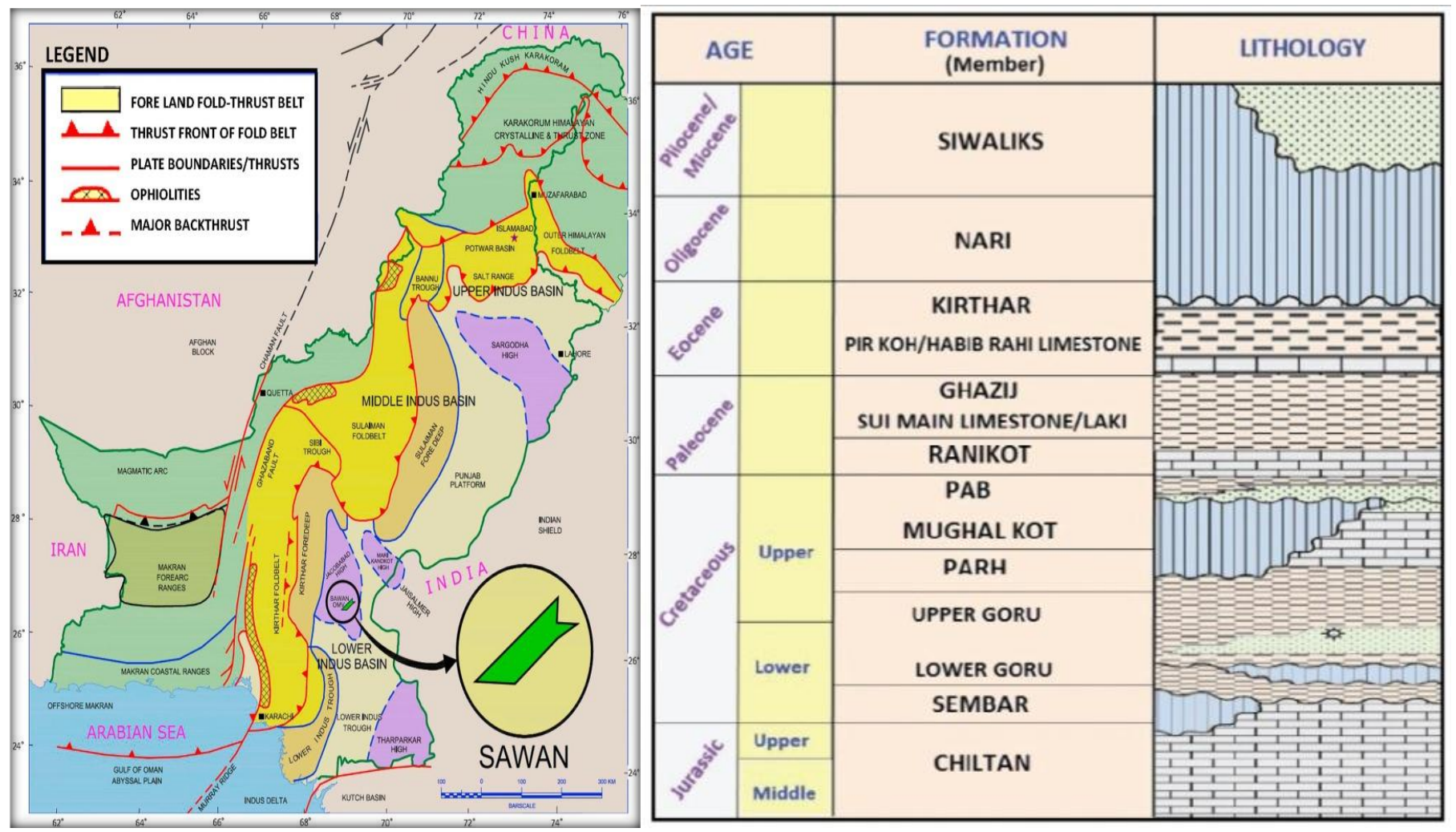

Figure 1: (a) Location map of the Pakistan after. (b) Stratigraphic column of middle Indus Basin. 


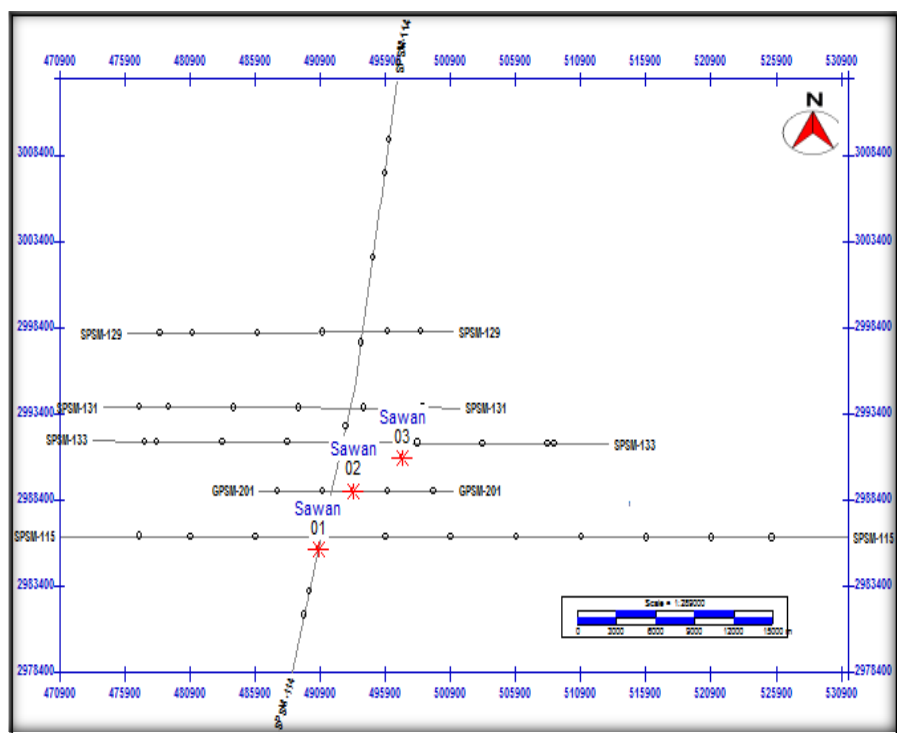

Figure 2: location base map of the study area showing different seismic lines.

\subsection{Methodology}

The data of seismic lines was acquired from LMKR after getting permission from DGPC. This data includes six seismic lines and three wells. The orientation of seismic lines with the location of wells is shown in the base map (Figure 1). Rock physics intends to portray rock properties in view of the conduct of seismic waves propagation through them [13]. This requires thought of how the composition of a stone directs its pressure strain relationship and hence seismic reaction. The impact of pore liquids is specifically compelling because of its immaterialness to the hydrocarbon industries. In a standard seismic elucidation work process shake material science is utilized to relate impedance and versatile parameters got from seismic information to particular rock properties [14]. This obliges what seismic information is physically fit for settling and the non-uniqueness related with a particular translation. Distinctive rock physics parameters which are computed in this research work are given underneath.

\subsection{Results and Discussion}

\subsection{Seismic Inversion}

Seismic inversion is the estimation of subsurface physical properties by using the seismic data as input. Seismic inversion can be applied "AFTER STACK" and "BEFORE STACK". Different supposition uses for BEFORE \& AFTER STACK inversions. The After-stack Inversion based on Zero offset assumption and before stack multi- offset assumption. For Inversion understanding of forward modelling is important because inversion is inverse of forward modelling. Work flow of Inversion is given below.

\subsection{Model Based Inversion}

There are different types of inversions here we only use the Model Base Inversion because they have high resolution then other (spark spike) types. Model Base Inversion is commonly use in industries. In Seismic inversion a single parameter called acoustic impedance play very important roll which is immediately recognizable. A model-based inversion of $2 \mathrm{D}$ seismic data was perform to calculate dimensional distribution of impedance(A=pv) in a study area. Amplitude \& layer property are the interface property, defined by acoustic impedance. For significant interpretation acoustic impedance $(A=p v)$ is used $[15,16]$. Zero phase statistical wavelet was extracted at well positions from data via a comparing filter between synthetic trace and seismic trace. By combining interpreted horizons and well log information a priori model (low impedance) is then constructed. Porosity and Acoustic impedance are usually inversely proportional to each other. Now porosity can be predicted in seismic reservoir characterization by using acoustic impedance from seismic inversion away from well position. The main objective is getting impedance of high resolution from low resolution seismic data through seismic inversion.

For Model based a widely applicable linear inversion problem-solving procedure is used. For This problem-solving procedure wavelet (W) and seismic trace $(S)$ were assumes and modifying initial model up to synthetic trace matching with real trace until acceptable level is not obtain or modifying geological model until seismic trace and synthetic trace error is not reduce [17]. Substantial knowledge of geology is required for making this method efficient form obtaining logical model. The essential approach utilized as a part of the calculation is to limit the accompanying capacity given in equation, as the fundamental suspicion of inversion is to quantify nonconformist amongst genuine and manufactured information [17].

J=weight $\mathrm{x}(\mathrm{S}-\mathrm{W} * \mathrm{R})+$ weight $2 \times\left(\mathrm{M}-\mathrm{H}^{*} \mathrm{R}\right)$

Where,

$\mathrm{S}=$ Real seismic trace,

$\mathrm{W}=$ Extracted wavelet,

$\mathrm{R}=$ Final reflectivity series,

M= Initial predicted model

$\mathrm{H}=$ Integration operator developing final impedance by convolution with final reflectivity(R)

Now above logical models' initial segment is the seismic trace and for the second portion of models is the underlying conjecture impedance. The product equips a "Constrained Model Inversion", is zero, and the last impedance esteems are balanced amongst upper and lower esteems [17]. The difficult obliged (well information) controls the little measure of commotion or error's in modelling. Extra data, for example, introductory figure model can likewise be fused by utilizing delicate obliged (variorum demonstrate) yet for the most part hard compelled are proposed for reversal system [17].

\subsection{Seismic To Well Correlation}

Seismogram is correlated with the line GPSM-201 where Sawan-02 well is located shown in figure below for the identification of exact location. Sonic and density log is used to generate reflectivity series.

Estimation of seismic wavelet is difficult due to its variation with frequency, time and with space [18]. There are two basic methodologies used for extraction of wavelet which are the statistical and deterministic techniques. If already well tie exist then deterministic approach is used and for statistical approach 
an average wavelet is calculated from a particular window of 2D seismic information [18,19]. Statistical wavelet is extricated from seismic data as shown in Figure 10 having zero phases.

Synthetic trace generated by convolution of computed reflectivity and source wavelet.

The phase of extracted wavelet is zero because it has maximum amplitude at $\mathrm{t}=0 \mathrm{~ms}$.

The range of frequency is from 5 to $50 \mathrm{~Hz}$ and average amplitude of source wavelet is $0.50 \mathrm{~Hz}$.

\subsection{Petrophysics}

4.4.1 Zone A

Zone A lies in the upper part of the C-Interval, depth ranges from 3398m to 3470m (Figure 2). This zone dominantly contains clean sandstone which has high porosity, permeability and has good saturation of water so refers as conventional hydrocarbon zone. The density-neutron log indicates the presence of gas in this zone.

\subsubsection{Zone B}

In this zone the clean sandstone is sandwich between shale which has low porosity and permeability and good saturation of hydrocarbon (Figure 2) so this zone refers as unconventional hydrocarbon zone (Tight gas). The depth ranges from $3480 \mathrm{~m}$ to $3510 \mathrm{~m}$. Several techniques exist that allow natural gas to be extracted in unconventional hydrocarbon zone including fracturing and acidizing.

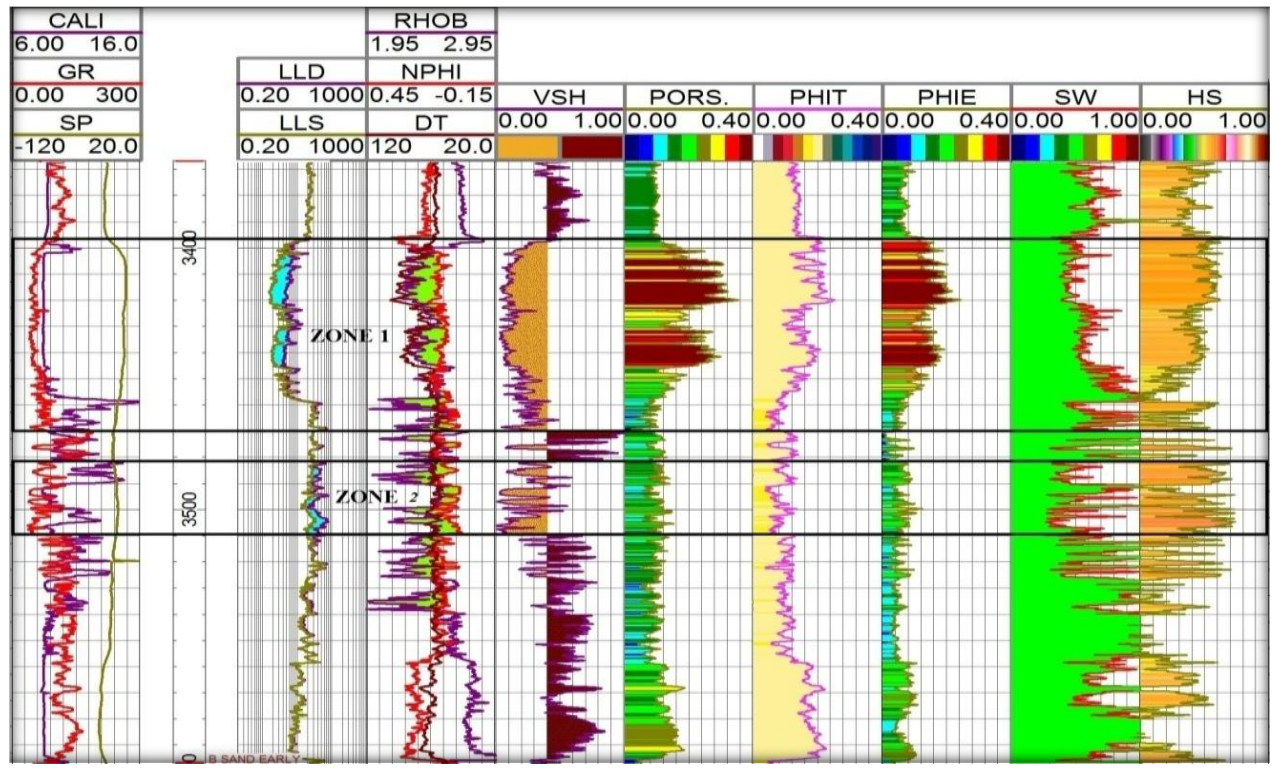

Figure 3: Figure showing the interpreted well log of C-Intervel of Goru formation, Sawan 2 well.

Generalised result of the well log analysis has been enlisted in table 1 given below.

Table 1: Table showing petrophysical result of Zone A and B.

\begin{tabular}{|l|l|}
\hline Petrophysical Properties & Average Value \\
\hline Volume of shale & $20 \%$ \\
\hline Hydrocarbon saturation & $47 \%$ \\
\hline Effective porosity & $9 \%$ \\
\hline Total porosity & $11 \%$ \\
\hline Water saturation & $53 \%$ \\
\hline
\end{tabular}

\subsection{Elastic Rock physics Properties at In-situ Conditions}

Different rock physics parameters are calculated, like Bulk modulus, shear modulus density and poisson's ratio from the well log data by using different relation as given below [20]. The result of all these parameters are displayed in figure 4 and 5 .

$$
\begin{gathered}
K=\rho\left(V_{p}^{2}-\frac{4}{3} V_{s}^{2}\right) \\
\mu=\rho V_{s}^{2} \\
\rho=0.31 * V_{p}^{.25} \\
\sigma=0.5\left(V_{p}{ }^{2}-2 V_{s}^{2}\right) /\left(V_{p}{ }^{2}-V_{s}{ }^{2}\right)
\end{gathered}
$$


low at the points where there are high porosity values as shown in figure 7. Density also has the same trend as the velocity that is high where porosity is high and vice versa as shown in figure 7.

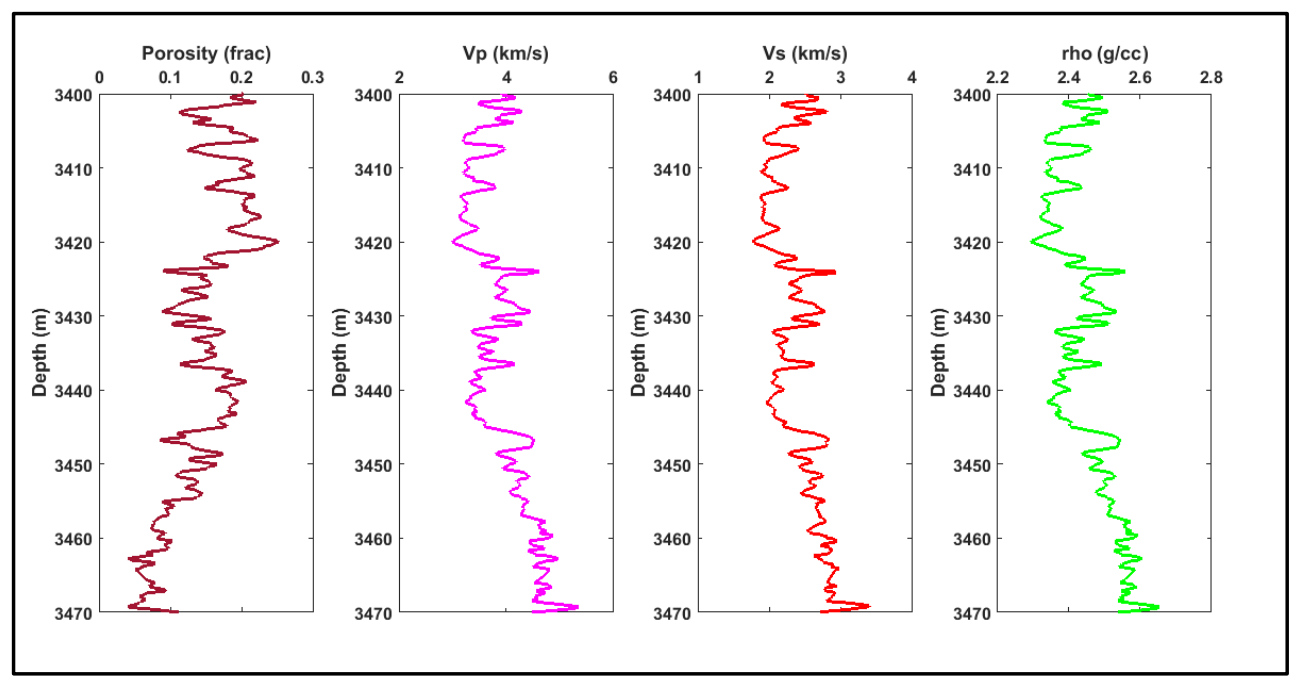

Figure 4: In-situ rock physics parameters calculated from Sawan 02 well.

Figure shows the saturated bulk and shear modulus at the initial conditions calculated from the well data by using the above relation. Elastic moduli have high values where porosity is low and high where porosity is high.

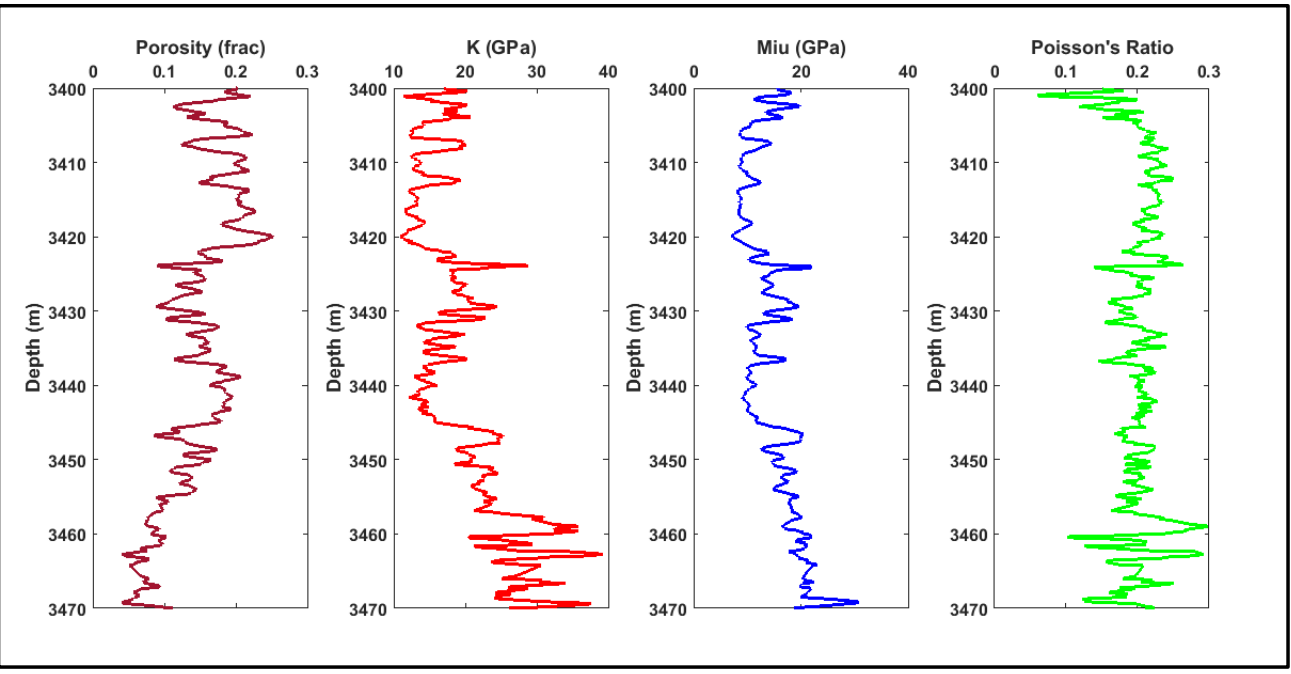

Figure 5: In-situ rock physics parameters calculated from Sawan-02.

\subsection{Elastic Properties after Fluids Substitution by using Gassmann Fluid Substitution}

Variation of porosity along with depth is shown in the figure. Ksat. for oil gas and water for $100 \%$ saturation shows variation at maximum value of porosity. Small overlapping is observed in oil and gas. At depth $3420 \mathrm{~m}$ porosity is maximum and variation is observed between oil and water. Vpsat and Vs sat also shows the variation with depth. At highest porosity Vp saturated shows small differentiation between oil and water, whereas Vs show no such variation as Vs is insensitive to fluid.

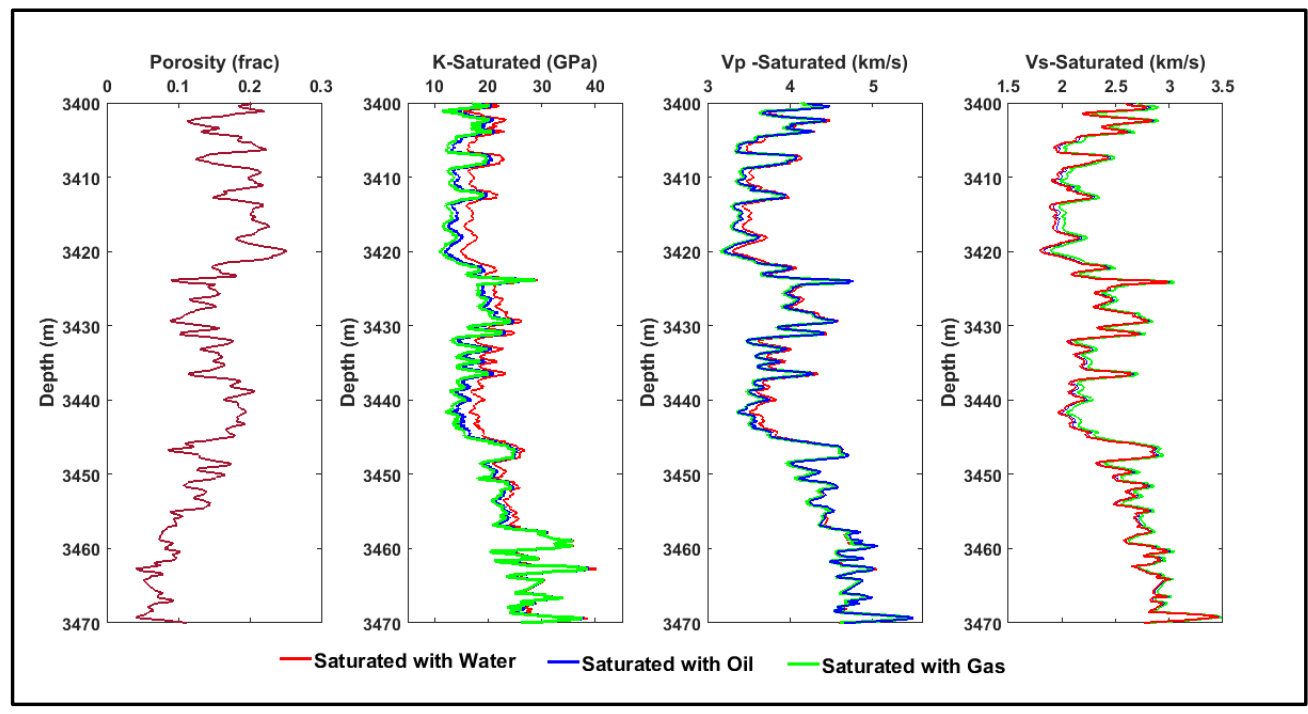


Figure 6: Bulk modulus, $\mathrm{P}$ wave velocity and $\mathrm{S}$ wave velocity after fluid substitution.

4.6.1. Cross-plot of Bulk Modulus versus Porosity after fluid substitution

Bulk modulus after the fluid substitution plotted along the porosity is shown in figure 6. Bulk modulus is calculated with three different types of fluids namely water oil and gas. Bulk modulus has a high value in case of water bearing reservoir then that of oil and gas bearing reservoir, and the gas bearing reservoir has the lowest value. The difference between water oil and gas saturated bulk modulus becomes more as porosity increase and is less where porosity is low as shown in figure 7.



Figure 7: Cross plot of the bulk modulus versus porosity for three different types of fluid saturation.

4.6.2. Cross-plot of $P$ wave velocity versus Porosity after fluid substitution

$\mathrm{P}$ wave velocity after the fluid substitution plotted along the porosity is shown in figure 8. $\mathrm{P}$ wave velocity is calculated with three different types of fluids namely water oil and gas. $\mathrm{P}$ wave velocity has a high value in case of water bearing reservoir then that of oil and gas bearing reservoir, and the gas bearing reservoir has the lowest value. The difference between water oil and gas saturated P wave velocity becomes more as porosity increase and is less where porosity is low as shown in figure 8 .

4.6.3. Cross-plot of $S$ wave velocity versus Porosity after fluid substitution

$S$ wave velocity after the fluid substitution plotted along the porosity is shown in figure 9 . S wave velocity is calculated with three different types of fluids namely water, oil and gas. $S$ wave velocity has a low value in case of water bearing reservoir then that of oil and gas bearing reservoir, and the gas bearing reservoir has the highest value. The difference between water oil and gas saturated $\mathrm{S}$ wave velocity becomes more as porosity increase and is less where porosity is low as shown in figure 9.

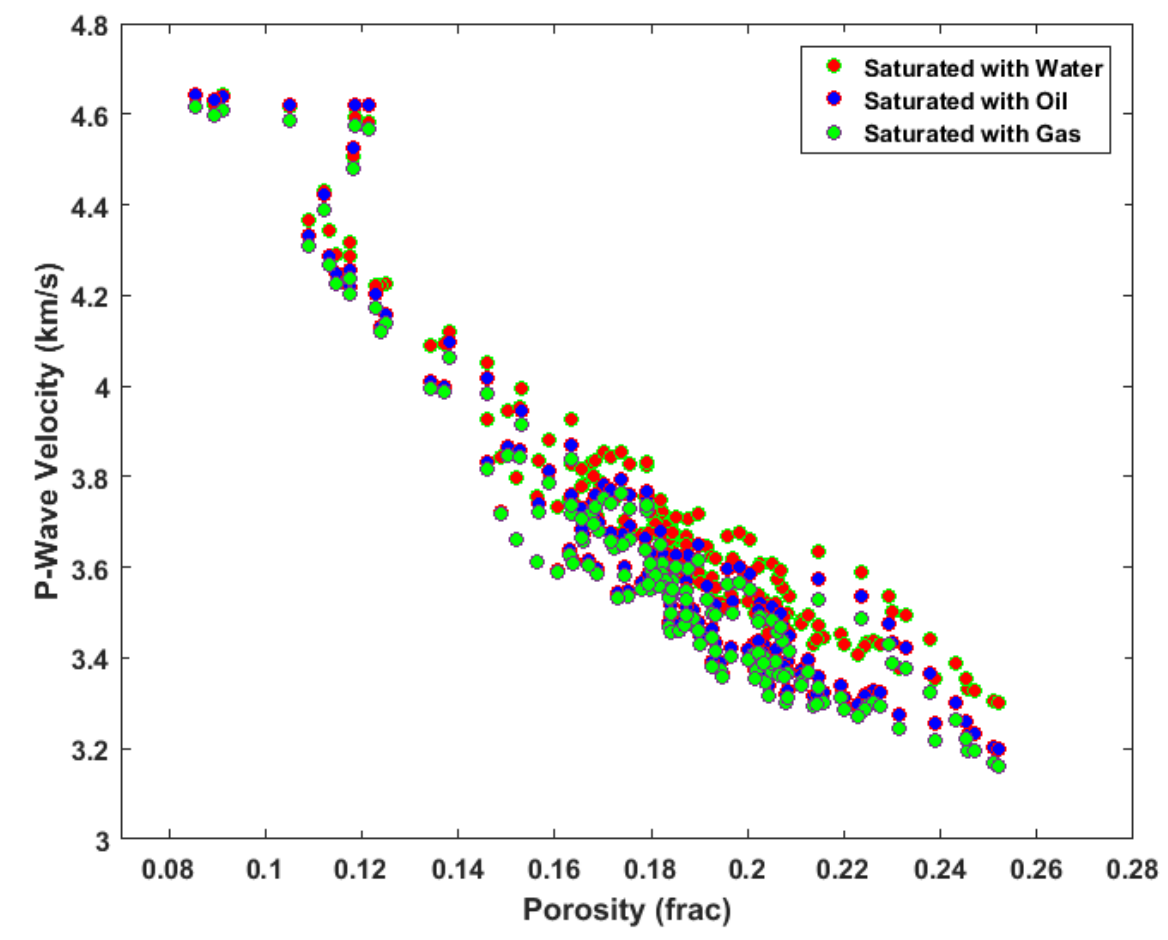

Figure 8: Cross plot of the $\mathrm{P}$ wave velocity versus porosity for three different types of fluid saturation. 




Figure 9: Cross plot of the $S$ wave velocity versus porosity for three different type's fluid saturation.

\subsection{Extracted Wavelet}

For correlation of extracted and inverted reflectivity from seismic at well site a constant phase wavelet was estimated shown in fig. 10 below. The $0.83 \%$ correlation found between real and synthetic trace. The length $2100-2400 \mathrm{~ms}$ is set for window for the extraction of wavelet having wavelength of $100 \mathrm{~ms}$. The procedure utilizing for wavelet use seismic data close to the well logs.

Seismic inversion depends on the convolution model i.e. synthetic trace is then got by convolving extracted wavelet and reflectivity series [21,22]. Required results for inversion and seismic interpretation, the wavelet must be minimum or zero phase. Phase shift amount for input wavelet influences the inversion results greatly.

If the phase shift is greater the error will be higher in resultant impedance [21].

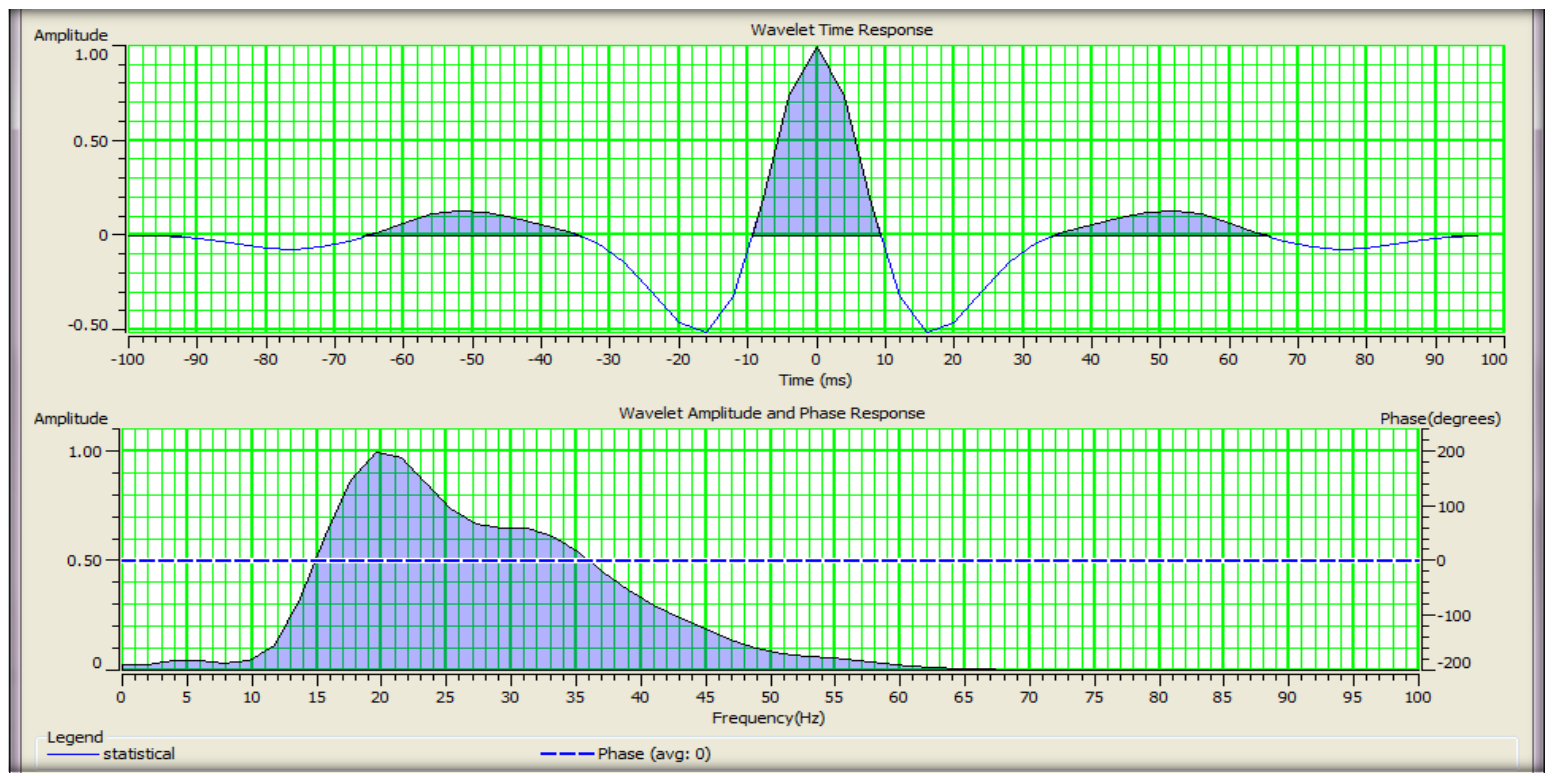

Figure 10: Statistical wavelet is extracted with amplitude spectra. Dotted line denotes average phase of wavelet. 


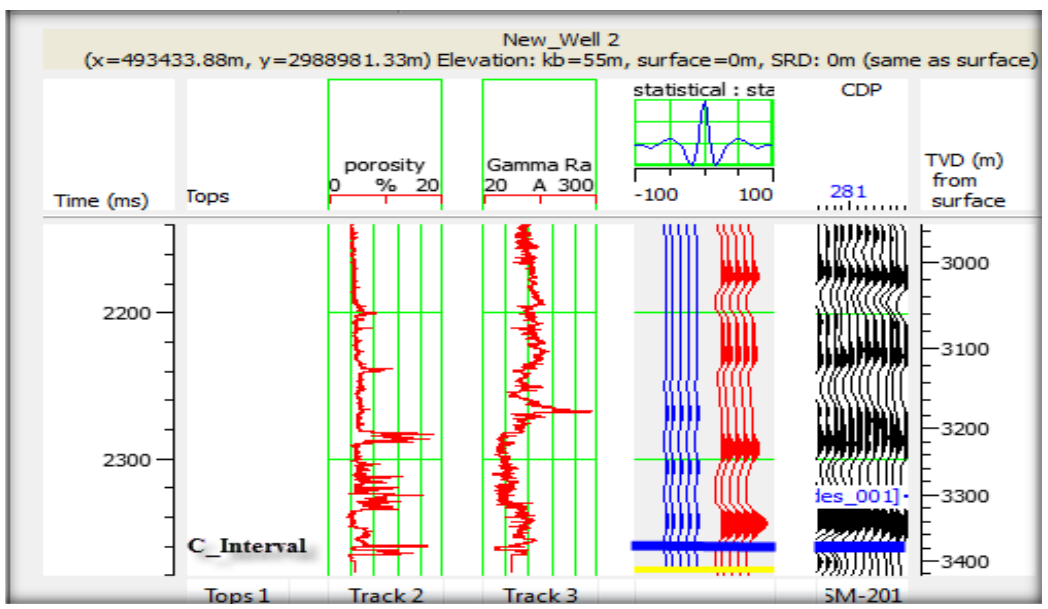

Figure11: Shows blue synthetic and red extracted traces at Sawan 02 well.

For confirmation of seismic and synthetic matching, Seismic section and synthetic trace are compared at well Sawan 02. There correlation between them as shown in below.

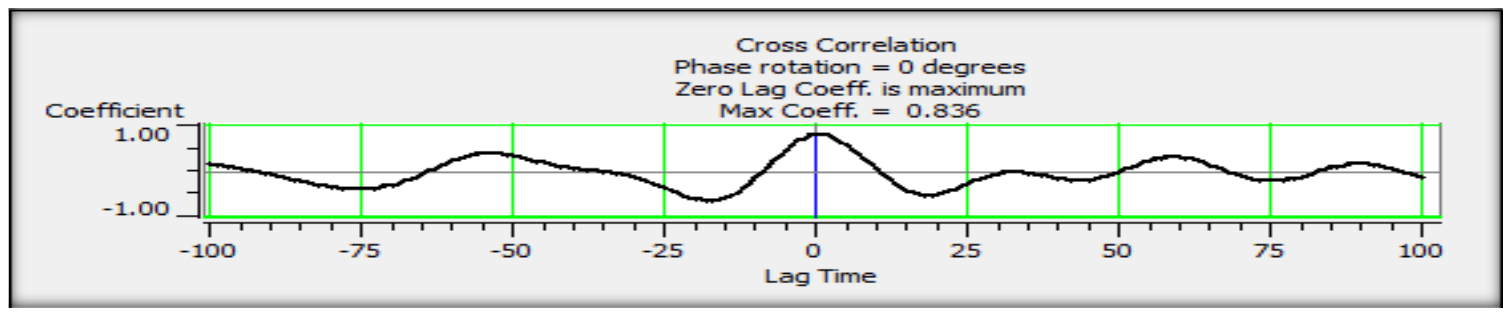

Figure 12: Shows Correlation coefficient for seismic to well tie.

\subsubsection{Initial Model/Low frequency Model}

For acoustic impedance there are two terms utilized that is absolute and relative. In low frequency model generation relative acoustic impedance does not incorporated, it is used for quantitative interpretation due to its relative layer property. Through low frequency range from 0 to $15 \mathrm{~Hz}$ absolute impedance is generated by inverting given amplitude data given to inversion calculation [23].

Low frequencies are added in model base inversion instead of forming different low frequency model. For quantitative and qualitative interpretation absolute acoustic impedance is used [16]. A low impedance demonstrate created for display based reversal is appeared in Figure 15. To get absolute acoustic impedance from reversal comes about a low frequency model must be included from hard limitations, for example, sonic and density logs.

In model base inversion we generate low impedance model after well to seismic tie which is given below is figure 15 absolute acoustic impedance obtain from inversion results.

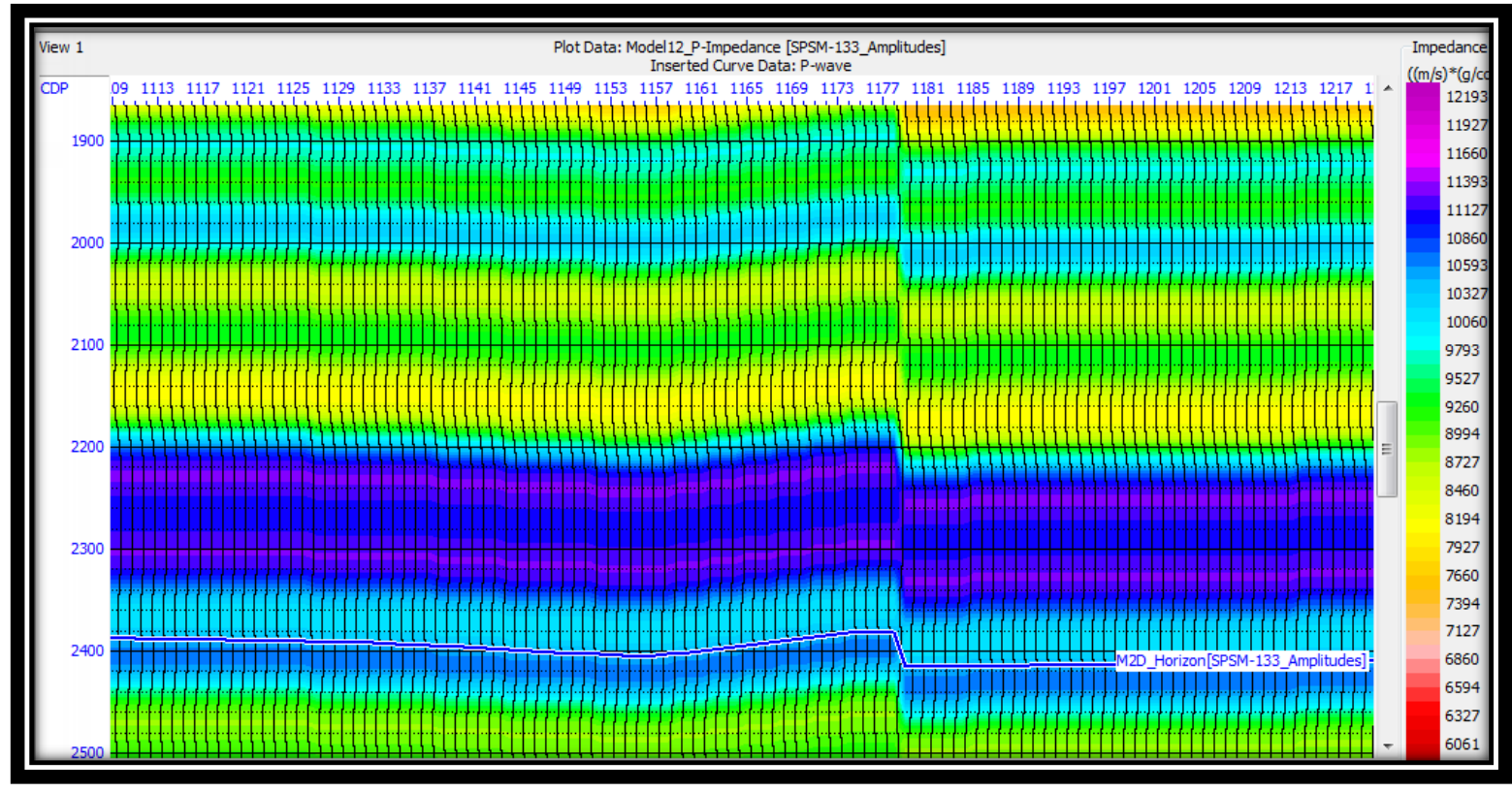

Figure13: Initial model of line PSM-133.

\subsection{Inversion Analysis}

The examination at the well area the model base inversion was performed with respect to the given 2D seismic data. The range set for statistical wavelet extraction $2100-2600 \mathrm{~ms}$ in time window. For balancing extracted wavelet frequency range comparing inverted trace at well site and synthetic trace. There is high correlation coefficient about 0.99 is obtain by correlation of red and black trace as shown in Figure 6.7 below. 




Figure 14: Shows inversion analysis at Sawan-02 well.

The consequences of Model Based reversal for line 201, shown in Figure $(13,14)$. Post stack inversion is apply only zone of interest for this time window 2100-2600 was selected. Acoustic impedance of different layer estimated by variation in colours obtains from inversion. Our zone lying at $2320 \mathrm{~ms}$ is known as $\mathrm{C}$ interval of lower Goru formation. Petrophysics comes about talked about in past section likewise feature a good zone at a similar profundity. The high impedance green colour lying above the Low impedance layer and is consist of shale and acting as a cap rock for $\mathrm{C}$ interval [17]. The low impedance layer at $2320 \mathrm{~ms}$ demonstrates a sidelong squeeze out towards SE. This demonstrates thickness of C-interval is diminishing towards SE compartment and making a stratigraphic trap. Sawam-02 lies According to data given by Co-chief at OMV, Sawan-02 is at development stage. In lower Goru formation shale sand packages observed through alternate high low layer impedance patterns. There is also found impedance layer at $2220 \mathrm{~ms}$ but cannot act as a reservoir because there is high impedance layer lying below. Laterally good variations founds in the acoustic impedance through inversion illustration of shale sequence.



Figure 15: Shows inverted impedance of line 201 from inversion.

\subsection{Porosity Calculation}

In the reservoir characterization two parameters porosity and permeability are important parameters but its estimation is quite difficult due to presence of variation at reservoir level but at well site can be measured. Reservoir rock porosity is important, but its quantitative estimation is difficult because due to presence of shale at reservoir level or there are various types of porosity and can be calculated by different methods.

Arrangement of previously mentioned quandary can be estimated by coordination of Seismic inversion petro and rock physics analysis though these methods we get suitable results. A definitive objective of seismic reversal is to give models of acoustic impedance as well as of other reservoir properties, for example, effective porosity for bury well districts [24]. As impedance diminishes with increment in porosity esteem as the relation found between impedance and porosity is inverse. The connection created for porosity computation is given as takes after:

Porosity $=0.003^{*} \mathrm{AI}-19.79$ 


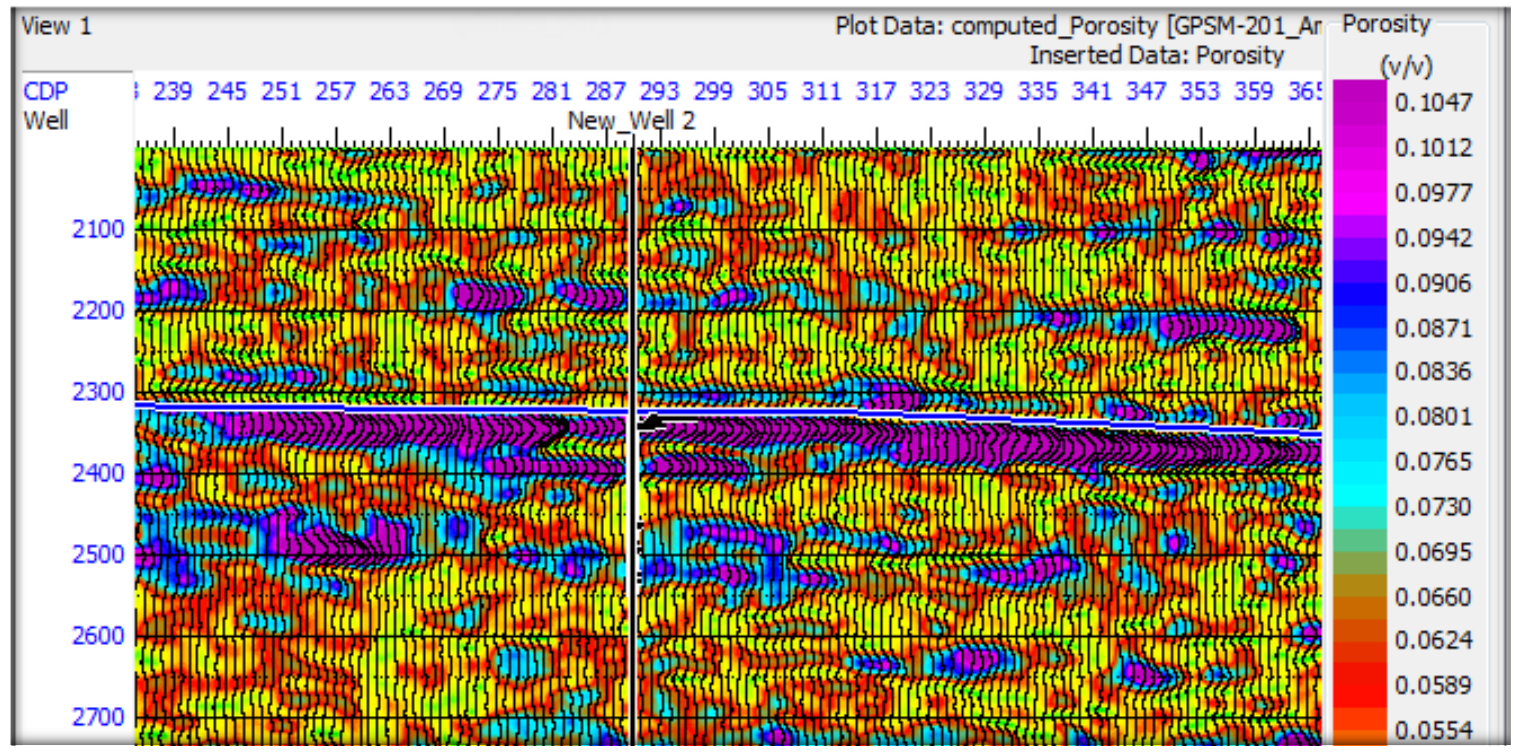

Figure 16: Shows the porosity distribution on Cross section of line GPSM-201.

The porosity circulation on Cross segment of line GPSM-201 for C-interval is appeared in Fig 16 . The cross segment demonstrates the dispersion of porosity over the supply scale. The porosity values are matching, assessed at well area by petrol physics and evaluated from seismic inversion.

\subsection{Conclusions}

This examination work has been finished by utilizing six seismic lines and three wells. The point of this examination work is to locate the structural trap and reservoir properties of C-interval of Lower Goru Formation by methods for seismic and following petrophysical interpretation:

- Petrophysical part of the exploration incorporates understanding of one well I-e Sawan-02.From well log translation of Sawan-02 it is reasoned that the beneficial zone of Sawan zone is C-interim of Lower Goru Formation which is additionally subdivided into two zones I-e hydrocarbon zone, water zone, and dry zone relies on the porosity, permeability, water saturation \& hydrocarbon saturation.

- Presence of gas in Sawan-02, is effecting Neutron-Density log in the C-interval of Lower Goru Formation.

- Results of Model base inversion demonstrate the high impedance esteems beneath or acoustic impedance above and below C Interval vary. Shale is identifying by high acoustic impedance which may go about as a cap rock of reservoir consist of C_sand. The impedance log at Sawan-02 demonstrates a low impedance inconsistency at time $3390 \mathrm{~ms}$ that is location of C-sand.

- Acoustic impedance values calculated by Model Base Inversion is 8530-9039 (m/s)*(g/cc) at reservoir level and according to Ibrahim.,(2007) values of impedance for good sand is from 8000 to $10000(\mathrm{~m} / \mathrm{s})^{*}(\mathrm{~g} / \mathrm{cc})$.

- The porosity calculation on Cross segment of line GPSM_201 for C-interval also done by inversion. The cross segment demonstrates the dispersion of porosity over the supply scale. The porosity values assessed at well area by petro physics matches with the value evaluated from seismic inversion.

- Porosity variation with depth confirms that Ksat shows better differentiation than Vp and Vs, as Vs is less sensitive to fluid.

- Cross plot analysis of rock physics parameter for three type of fluid also confirm that Ksat clearly separates the oil, gas and water, whereas small overlapping is observed in all other cross plots of other rock physics parameter.

- In this study we have recognized new areas where porosity distribution is maximum and is potential site which is suitable for new well.

\section{References}

[1] V.N. Quadri, and S.M. Shuaib, “Hydrocarbon Prospects of Southern Indus Basin, Pakistan," American Association of Petroleum Geologist Bulletin, Vol. 70, Pp. 730-747, 1986.

[2] F.K. Bender, and H.A. Raza, “Geology of Pakistan, Cambridge University Press.” Pp. 445, 1995.

[3] I.B. Kadri, “Petroleum Geology of Pakistan,” Pakistan Petroleum Limited, Karachi, Pakistan. P. 246, 1995.

[4] G.B. Asquith, and C.R. Gibson, "Basic well log analysis for geologists, American Association of Petroleum Geologists," Tulsa, Pp. $216,1982$.

[5] G. Asquith, and D. Krygowski, “Basic Well Log Analysis American Association of Petroleum Geologist,” Tulsa, Pp. $244,2004$.

[6] M.H. Rider, “The Geological Interpretation of Well Logs: 2nd eds. Gulf Pub Corp, Houston,” Pp. 280, 1996.

[7] Schlumberger, "Log Interpretation, Principles and Applications," Schlumberger Educational Services, 1989.

[8] A.R. Brown, "Seismic attributes and their classification," The leading edge, Vol. 15, Pp. 1090-1090, 1996.

[9] Q. Yuedong, and A. Hongwei, "Study of petrophysical parameter sensitivity from well log data," Applied Geophysics, Vol. 4, Pp. 282-287, 2007.

[10] A.H. Kazmi, and M.Q. Jan, “Geology \& Tectonics of Pakistan”, Graphic Publishers, Karachi, Pakistan, 1997.

[11] S.M.I. Shah, "Stratigraphy of Pakistan," Mem.12, Geological Survey of Pakistan, Quetta. Pp. 465, 1977.

[12] T. Azeem, W. Yanchun, P. Khalid, L. Xueqing, F. Yuan, and C. Lifang, "An application of seismic attributes analysis for mapping of gas bearing sand zones in the Sawan gas field Pakistan," Acta Geod. Geophys, Vol. 51, Pp.723-744, 2016. http://dx.doi.org/10.1007/s40328-015-0155-z.

[13] M.E. Badley, "Practical Seismic Interpretation, D. Riedel Publishing Company and International Human Resources Development Cooperation," Dordrecht, Holland, Pp. 287, 1985.

[14] S. Chopra, and J.K. Marfurt, "Evolution of seismic interpretation during the last three decades," The leading edge, Vol. 31, Pp. 654-676, 2012.

[15] D.A. Cooke, and W.A. Schneider, “Generalized linear inversion of reflection seismic data,” Geophysics, Vol. 48, Pp. 665-676, 1983.

[16] M.B. Dobrin, and C.H. Savit, “Introduction to Geophysical Prospecting, 4th Edition,” McGraw-Hill Book Company, London. Pp. $348,1988$. 
[17] P.E. Gavotti, D.C. Lawton, G.F. Margrave, and J.H. Isaac, "Post-stack inversion of the Hussar low frequency seismic data," Geo-convention Canada, 2014.

[18] O. Yilmaz, "Seismic Data Processing," Society of Exploration Geophysics, Tulsa, USA, 1987.

[19] H.N. Al-Sadi, “Seismic Exploration Technique and Processing,” Birkhauser Verlag, Basel p. 215, 1980.

[20] J. Pujol, "Elastic wave propagation and generation in seismology," Cambridge University Press, United Kingdom. Pp. $439,2003$.

[21] W.M. Telford, L.P. Geldart, and R.E. Sheriff, “Applied Geophysics,” Cambridge University Press, Pp. 792, 1991.

[22] C. Jain, "Effect of seismic wavelet phase on post stack inversion," 10th Biennial International Conference \& exposition, Pp. 410, 2013.

[23] E.S. Robinson, and C. Coruh, “Basic Exploration Geophysics,” John Wiley and Sons, New York. Pp. 576, 1988.

[24] H.M. Anwer, T.M. Alves, A. Ali, and S. Asia, "Effects of sand-shale anisotropy on amplitude variation with angle (AVA) modelling : The Sawan gas field (Pakistan) as a key case-study for South Asia`s sedimentary basins," Journal of Asian Earth Sciences, Vol. 147, Pp. 516-531, 2017. doi: 10.1016/j.jseaes.2017.07.047. 